\title{
Microbiome definition re-visited: old concepts and new challenges
}

Gabriele Berg

Daria Rybakova

Doreen Fischer

Tomislav Cernava

Marie-Christine

Champomier Vergès

Trevor Charles

Xiaoyulong Chen

Luca Cocolin

Kellye Eversole

Gema Herrero Corral

Maria Kazou

Linda Kinkel

Lene Lange

Nelson Lima

Alexander Loy

James A. Macklin

Emmanuelle Maguin

Tim Mauchline

Ryan McClure

Birgit Mitter

Matthew Ryan

Inga Sarand

Hauke Smidt

Bettina Schelkle

Hugo Roume

G. Seghal Kiran

Joseph Selvin

Rafael Soares Correa de Souza

Leo van Overbeek

Brajesh K. Singh

Michael Wagner

Aaron Walsh

Angela Sessitsch

Michael Schloter 


\section{Video Byte}

Keywords: Microbiome, microbiome research, MicrobiomeSupport, microbiota, standardization, agriculture, medicine, microbial ecology, paradigm shift, coevolution, dysbiosis, microorganism, microbe, 16S rRNA, metagenomics, assemblage, co-occurrence analysis, mRNA, core microbiota, consortia

Posted Date: November 3rd, 2020

DOI: https://doi.org/10.21203/rs.3.rs-102129/v1

License: (9) This work is licensed under a Creative Commons Attribution 4.0 International License.

Read Full License 


\section{Abstract}

Microbiome research has consistently been placed in the spotlight over the past two decades, and has shown tremendous promise in the fields of medicine, environmental science, food production, and agriculture. Life on Earth does not exist without microbes, and we may benefit from learning more about them. Yet, there is no common understanding amongst researchers of what a 'microbiome' actually is. Researchers are now proposing a common definition of 'microbiome' to ensure better, more robust research across different disciplines. The authors build on the historical definition offered by Whipps and colleagues in 1988 using new research insights. Additionally, they highlight the importance of microbiomes as drivers for the health of many eukaryotic hosts, including humans and plants. The proposed amendments to the definition specify the elements of microbiome composition and their interactions. This revised definition was developed with input gathered during a workshop hosted by the EU-funded project MicrobiomeSupport in March 2019, and an online survey including more than 100 experts from around the world. 